\title{
Design of an UWB Bandpass Filter Using Dual MMR with Highly Attenuated Upper Stopband Using DGS
}

\author{
Aditi Sengupta $^{a^{*}, \text { Somdotta Roy Choudhury }}{ }^{\mathrm{b}}$, Santanu Das ${ }^{\mathrm{c}}$ \\ ${ }^{a}$ Department of Electronics \& Communication Engineering, Guru Nanak Institute of Technology, Kolkata- \\ 700114, India \\ ${ }^{b}$ Department of Electronics \& Telecommunication Engineering, Ramrao Adik Institute of Technology, D. Y. \\ Patil University Campus, Navi Mumbai-400706, India \\ ${ }^{c}$ Department of Electronics \& Telecommunication Engineering, Indian Institute of Engineering Science \& \\ Technology, Shibpur, Howrah -711103, India
}

Received: 15 September 2017; Accepted: 17 January 2018; Published: 08 May 2018

\begin{abstract}
A miniature sized microstrip UWB (ultra wideband) BPF (bandpass filter) having highly attenuated upper stop band performance using a dual MMR (multimode resonator) and the DGS (defected ground structure) is proposed. Combining these two topologies, a prototype of the proposed UWB BPF is fabricated using FR-4 substrate of $1.6 \mathrm{~mm}$ thickness with dielectric constant of 4.4. This BPF is modelled and simulated using Ansoft high frequency structure simulator (HFSS) Software. The simulated and measured results show a wide FBW (fractional bandwidth) of $119 \%$.The insertion loss is less than $-1.0 \mathrm{~dB}$ throughout the pass band of 2.78 to 10.95 GHz. All the ripples of return loss are lower than $-14 \mathrm{~dB}$ in the passband. The BPF has a high rejection of more than $-30 \mathrm{~dB}$ in the upper stop band up to $16.8 \mathrm{GHz}$. The simulated and measured group delays variation in the passband are found to be less than $0.2 \mathrm{~ns}$. The overall length of the resonator is $7 \mathrm{~mm}$.
\end{abstract}

Index Terms: UWB (ultra-wideband), BPF (band pass filter), MMR (multimode resonator), DGS (Defected ground structure), Stopband.

(C) 2018 Published by MECS Publisher. Selection and/or peer review under responsibility of the Research Association of Modern Education and Computer Science

\section{Introduction}

The FCC (Federal Communications Committee) authorized the unlicensed version of UWB frequency

* Corresponding author:

E-mail address: itsmeaaditi@gmail.com 
spectrum for wireless communication since 2002 [1]. One of the major component for an UWB communication system is bandpass filter with a FBW of more than $100 \%$. It is a challenge to design a BPF with compact size, wide bandwidth, low insertion loss and also wideband rejection. Reducing resonator size is an effective approach to miniaturize the filter size.

Generally two approaches are used to reduce the resonator size. One is to modify the physical structure. Another is to modify the traditional resonator to generate additional modes and behave as a MMR. Several researchers have proposed different UWB BPF structures [2-17]. In 1998, a lumped-element equivalent circuit was proposed for a dual mode dielectric-resonator BPF that included mode coupling, excitation, and I/O electrode coupling schemes [2]. In 2003, a broad bandpass filter was achieved with bandwidth extended to $70 \%$ from $40 \%$ [3]. The bandwidth was increased at $86.6 \%$ with the design of a ring resonator with a stub in 2004 [4]. In 2005, an UWB bandpass filter was achieved with five transmission poles. The construction of MMR using quarter-wavelength parallel coupled lines in the input and output ports was introduced [5]. In 2007, an UWB bandpass filter was fabricated with combination of high pass filter consisting of inter-digital capacitors and short-circuited stubs and low pass filter realized by non-uniform defected ground structure array [6]. An UWB BPF using stub loaded MMR was presented that achieved FBW of 114\% [7]. In 2009, one article described a class of recently developed MMR based bandpass filters for UWB transmission system with stepped-impedance or stub-loaded non-uniform configurations and analyzed their properties based on the transmission line theory [8]. A novel multimode bandpass filter with high and wide rejection band using an open stub was proposed with two functions, one is perturbation for the multimode operation and the other is zero point generation at the stop band for the stop band control [9]. An UWB BPF with notched band was developed in 2010, by inserting a parasitic coupled line to block any unwanted existing radio signals that may interfere with conventional UWB systems [10]. In 2011, compact UWB BPF using stub-loaded MMR was proposed where two transmission zeros generated by the stepped-impedance stub [11]. A super UWB BPF with FBW of $138 \%$ was proposed to realize a wider passband, based on a simplified composite right/left-handed transmission line (SCRLH TL), while the complementary split ring resonators were etched in the ground plane to achieve better performance of the upper stop band [12]. A novel UWB microstrip filter was proposed using short circuited stub with etched rectangular lattice and better return loss was achieved [13]. In 2014, an UWBBPF is constructed from the step impedance lowpass filter, optimum distributed high pass filter and four rectangular shaped DGS [14]. In 2015, an UWB bandpass filter was presented by stub-loaded MMR and a fanshape stub-loaded stepped impedance in the center. The length of coupled line produced odd mode frequencies and the stub-loaded stepped impedance effected even mode frequencies [15]. To achieve wideband common mode (CM) suppression and compact design simultaneously, the concept of half-mode DGS was introduced in the two stacked microstrip layers of an UWB BPF using half mode dumbbell DGS in 2016 [16].

In this paper, an UWB bandpass filter is realized by a dual MMR and narrow DGS slots. The main feature of the proposed filter is the incorporation of MMR with slots at the ground plane to increase the coupling level which in turn decreases the back radiation without wide aperture. The proposed BPF is modelled and simulated using Ansoft HFSS Software. The center frequency of the filter is $6.86 \mathrm{GHz}$ with a wide band rejection in the stop band. The passband covers the frequency range of $2.78-10.95 \mathrm{GHz}$ while the group delay variation in the passband is less than $0.2 \mathrm{~ns}$. The proposed structure is fabricated on a low cost FR-4 epoxy substrate with dielectric constant of 4.4 and thickness of $1.6 \mathrm{~mm}$ and has a compact size of $20 \mathrm{~mm} \times 13 \mathrm{~mm}$. The overall length of the resonator is $7 \mathrm{~mm}$. The fabricated structure is measured by Vector Network Analyzer (VNA). The simulation results are in good agreement with those obtained experimentally with the realized filter.

\section{UWB-BPF Design and Analysis}

In this paper, an UWB BPF is designed using a dual MMR with narrow transverse DGS slots as shown in Fig. 1. The input and output feeding lines are connected to the coupled lines on the top side of the substrate while the DGS is etched on the other side below the coupled lines. An array of four DGS is etched in the ground plane of a planar transmission line to achieve better stopband performance of the designed microstrip filter. The 
proposed MMR causes a high degree of coupling without any wide aperture in the ground plane. The absence of wide aperture underneath the MMR provides a reduction in back radiation.

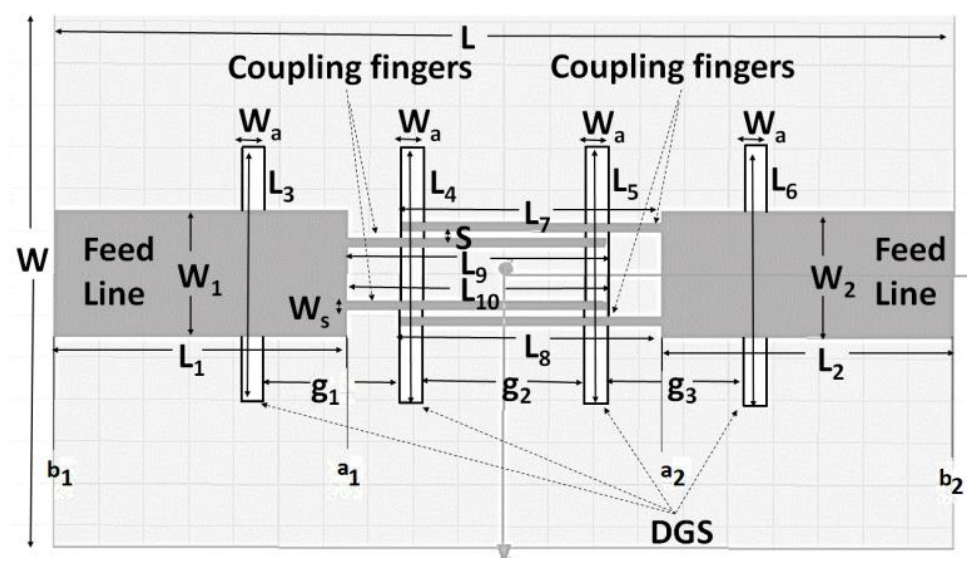

Fig.1. UWB band pass filter with DGS slots

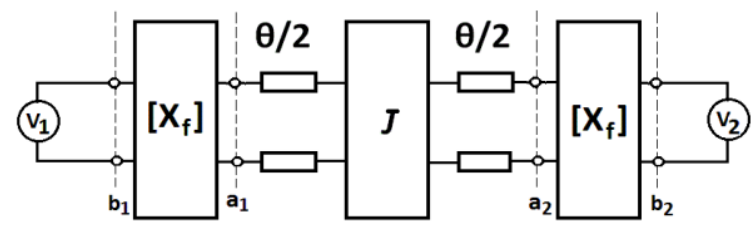

Fig.2. Equivalent transmission line network of the proposed UWB BPF

Very narrow transverse DGS slots are adopted to improve the upper stop band performance. The transmission line dimensions are selected on the basis of resonant length and quarter wave coupling. Proposed filter consists of an MMR, which are formed by two identical set of parallel coupled lines. The effects of variation of transverse type DGSs and coupling finger lengths of the filter structure are analysed on parameter basis.

Fig. 2 gives an equivalent transmission line network of Fig. 1, where the two ports $\left(b_{1}\right.$ and $\left.b_{2}\right)$ are far away from the reference planes $\left(\mathrm{a}_{1}\right.$ and $\left.\mathrm{a}_{2}\right)$. The entire layout is divided into two identical error terms $\left[\mathrm{x}_{\mathrm{f}}\right]$ and an equivalent J-inverter network. These error terms give the approximation of source excitation and inconsistency of MOM-based impedance definitions [17]. The MMR section can be extracted as a two port admittance matrix with discontinuity effects. The equivalent transmission line network allows the transformation of the admittance matrix into a J-inverter susceptance $(J)$ and two electrical lengths $(\theta / 2)$, which represent its series capacitive coupling and equivalent phase shifts, respectively. The total electric length of coupled line resonator is $\varphi=\theta / 2+\theta / 2[18]$.

\subsection{Effect of DGS width}

The bottom view of the BPF structure is shown in Fig. 3(a). The variation of filter performances due to change in defected ground array width $\left(\mathrm{W}_{\mathrm{a}}\right)$ is shown in Fig. 3 (b) and (c). Table 1 shows the FBW variation for different array width. For the smallest array width $\left(\mathrm{W}_{\mathrm{a}}=0.3 \mathrm{~mm}\right)$, the passband bandwidth is smallest and $\mathrm{S}_{11}$ (in $\mathrm{dB}$ ) is lower than $-11 \mathrm{~dB}$. As the array width increases, $\mathrm{S}_{11}$ in the passband exceeds $-11 \mathrm{~dB}$. However, the number of poles remain nearly constant (2 poles) in the passband. The zeros in the stop band move towards its edges as the slot width increases. 

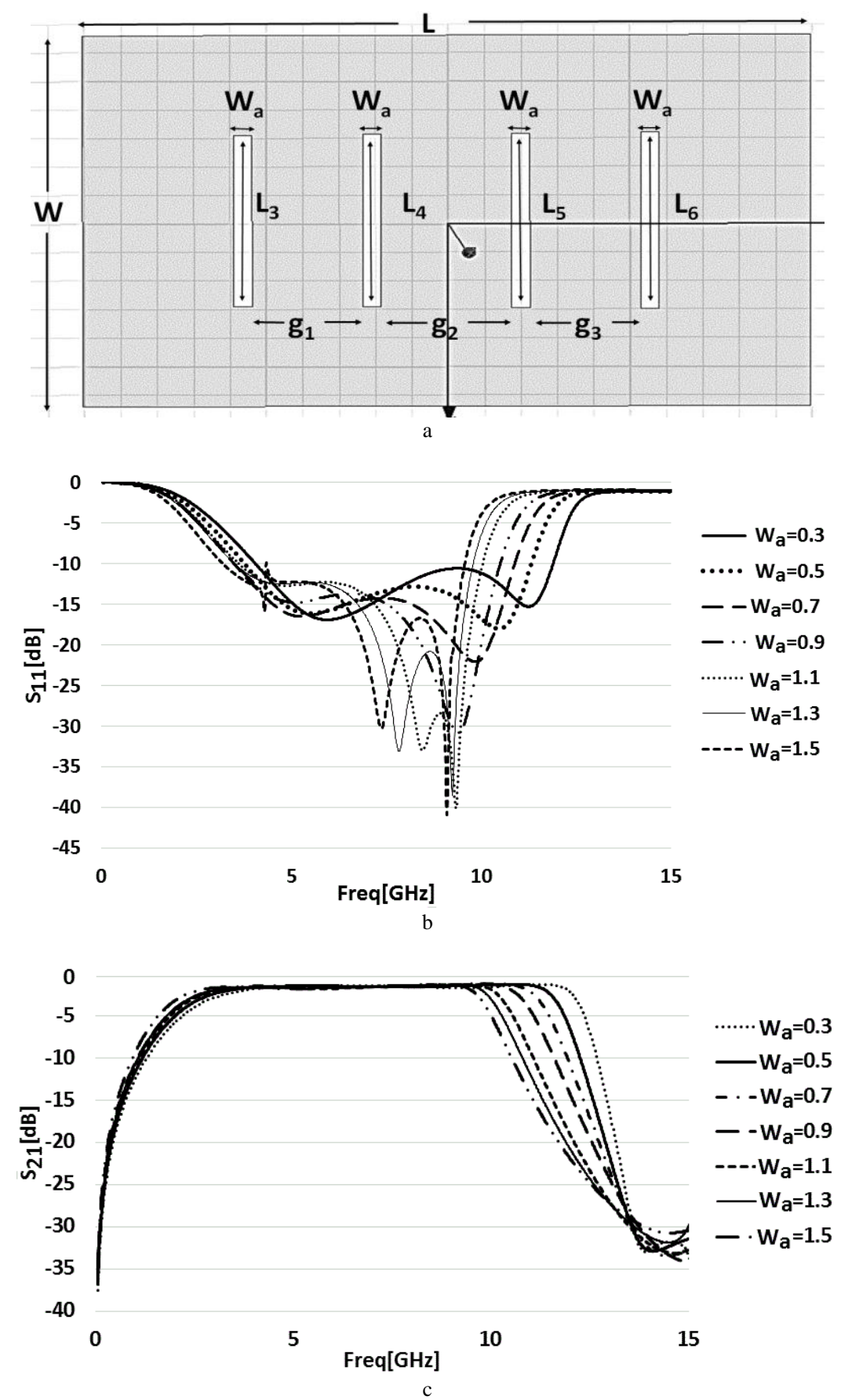

Fig.3. (a) Bottom view of the designed BPF; (b) $\mathrm{S}_{11}$ performance and (c) $\mathrm{S}_{21}$ performance against different DGS widths $\left(\mathrm{W}_{a}\right)$. 
Table 1. Effect of the DGS widths

\begin{tabular}{ccllc}
\hline Width $\left(\mathrm{W}_{\mathrm{a}}\right)(\mathrm{mm})$ & Band Width $(\mathrm{GHz})$ & FBW & 1st zero & 2nd zero \\
\hline 0.3 & $4.01-11.95$ & 99.4 & 0.11 & 13.92 \\
0.5 & $3.3-11.03$ & 107.88 & 0.095 & 14.04 \\
0.7 & $2.78-10.95$ & 118.24 & 0.09 & 14.3 \\
0.9 & $2.77-10.1$ & 113.9 & 0.086 & 14.48 \\
1.1 & $2.75-9.74$ & 111.92 & 0.081 & 14.66 \\
1.3 & $2.74-9.51$ & 110.53 & 0.074 & 14.84 \\
1.5 & $2.72-9.3$ & 109.48 & 0.07 & 15.32 \\
\hline
\end{tabular}

\subsection{Effect of DGS array gap}

Considering the bottom view of the BPF as shown in Fig. 3 (a), the effect of DGS array gaps $\left(g_{a}\left(=g_{1}=g_{3}\right)\right.$ and $\mathrm{g}_{2}$ ) on the filter performances is shown in Fig. 4 (a) and (b).
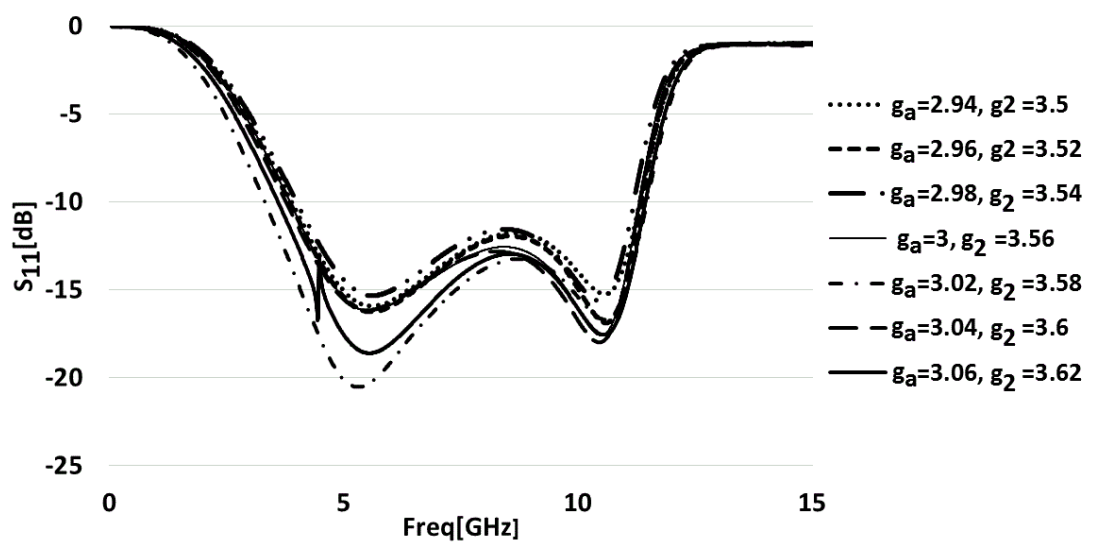

a

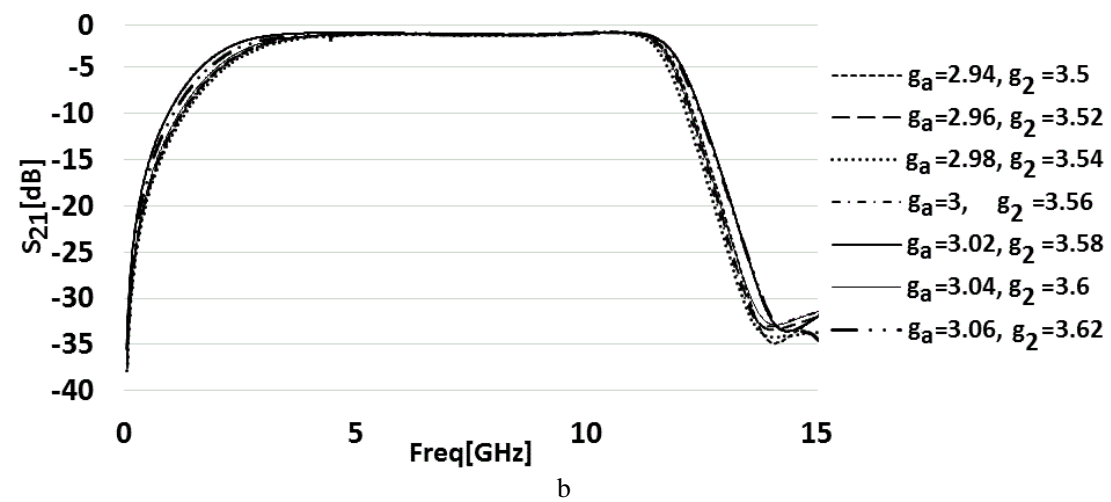

Fig.4. (a) $S_{11}$ performance and (b) $S_{21}$ performance for different DGS array gaps $\left(g_{a}\left(=g_{1}=g_{3}\right)\right.$ and $\left.g_{2}\right)$. 
Table 2. Effect of DGS array gaps

\begin{tabular}{lllll}
\hline $\begin{array}{l}\mathrm{Gap}(\mathrm{g})(\mathrm{mm}) \\
\mathrm{g}_{\mathrm{a}}=\mathrm{g}_{1}=\mathrm{g}_{3}, \mathrm{~g}_{2}\end{array}$ & Band Width $(\mathrm{GHz})$ & FBW & 1st zero & 2nd zero \\
\hline $\mathrm{g}_{\mathrm{a}}=2.94, \mathrm{~g}_{2}=3.5$ & $3.32-11.3$ & 109.16 & 0.1 & \\
$\mathrm{~g}_{\mathrm{a}}=2.96, \mathrm{~g}_{2}=3.52$ & $3.34-11.29$ & 108.68 & 0.095 & 13.88 \\
$\mathrm{~g}_{\mathrm{a}}=2.98, \mathrm{~g}_{2}=3.54$ & $3.36-11.28$ & 108.19 & 0.09 & 13.97 \\
$\mathrm{~g}_{\mathrm{a}}=3, \mathrm{~g}_{2}=3.56$ & $3.4-11.27$ & 107.29 & 0.088 & 13.99 \\
$\mathrm{~g}_{\mathrm{a}}=3.02, \mathrm{~g}_{2}=3.58$ & $3.41-11.26$ & 107.02 & 0.084 & 14.02 \\
$\mathrm{~g}_{\mathrm{a}}=3.04, \mathrm{~g}_{2}=3.61$ & $3.3-11.25$ & 109.27 & 0.08 & 14.13 \\
$\mathrm{~g}_{\mathrm{a}}=3.06, \mathrm{~g}_{2}=3.62$ & $3.42-10.89$ & 104.4 & 0.07 & 14.31 \\
\hline
\end{tabular}

As the gap value increases, although the FBW is nearly constant, but the zeros in the stop band move slightly towards its edges. So the variation of ' $g$ ' has negligible effect on the resonant modes of the filter and the number of poles remain constant ( 2 poles). The fractional bandwidth (FBW) and the frequency ranges $\left(\mathrm{S}_{11}<-12 \mathrm{~dB}\right)$ against the array gap variations are given in Table 2 above.

\subsection{Effect of DGS length}

The effect of DGS lengths $\left(\mathrm{L}_{3}, \mathrm{~L}_{4}, \mathrm{~L}_{5}\right.$ and $\left.\mathrm{L}_{6}\right)$, on the filter performances is shown in Fig. 5 (a) and (b), considering the bottom structure of BPF as shown in Fig. 3 (a). Table 3 shows the FBW variation for $S_{11}<-13$ $\mathrm{dB}$ versus array lengths. For small lengths $\left(\mathrm{L}_{3}=5.2 \mathrm{~mm}, \mathrm{~L}_{4}=5.26 \mathrm{~mm}, \mathrm{~L}_{5}=5.32 \mathrm{~mm}, \mathrm{~L}_{6}=5.38 \mathrm{~mm}\right)$, the passband bandwidth is small and $S_{11}\left(\right.$ in $\mathrm{dB}$ ) is lower than $-13 \mathrm{~dB}$. As the defected ground array length increases, $S_{11}($ in $\mathrm{dB})$ in the passband exceeds $-13 \mathrm{~dB}$.

Table 3. Effect of DGS lengths

\begin{tabular}{lcccc}
\hline Length $(\mathrm{L})(\mathrm{mm})$ & Band Width $(\mathrm{GHz})$ & FBW & 1st zero & 2nd zero \\
\hline $\mathrm{L}_{3}=5.2, \mathrm{~L}_{4}=5.26$, & $4.12-11.19$ & 92.3 & 0.08 & 15.95 \\
$\mathrm{~L}_{5}=5.32, \mathrm{~L}_{6}=5.38$ & & & & \\
$\mathrm{~L}_{3}=5.4, \mathrm{~L}_{4}=5.46$, & $4.1-11.24$ & 93 & 0.078 & 15.78 \\
$\mathrm{~L}_{5}=5.52, \mathrm{~L}_{6}=5.58$ & & & & \\
$\mathrm{~L}_{3}=5.6, \mathrm{~L}_{4}=5.66$, & $4-11.3$ & 95 & 0.075 & 15.54 \\
$\mathrm{~L}_{5}=5.72, \mathrm{~L}_{6}=5.78$ & & & & \\
$\mathrm{~L}_{3}=5.8, \mathrm{~L}_{4}=5.86$, & $3.8-11.33$ & 99 & 0.069 & 15.24 \\
$\mathrm{~L}_{5}=5.92, \mathrm{~L}_{6}=5.98$ & & & & \\
$\mathrm{~L}_{3}=6, \mathrm{~L}_{4}=6.06$ & $3.5-11.423$ & 106.27 & 0.065 & 14.14 \\
$\mathrm{~L}_{5}=6.12, \mathrm{~L}_{6}=6.18$ & & & & \\
$\mathrm{~L}_{3}=6.2, \mathrm{~L}_{4}=6.26$, & $3.601-11.425$ & 104.1 & 0.062 & 13.53 \\
$\mathrm{~L}_{5}=6.32, \mathrm{~L}_{6}=6.38$ & & & & \\
$\mathrm{~L}_{3}=6.4, \mathrm{~L}_{4}=6.46$, & $3.6-11.43$ & 104.19 & 0.06 & 12.9 \\
$\mathrm{~L}_{5}=6.52, \mathrm{~L}_{6}=6.58$ & & & & \\
\hline
\end{tabular}



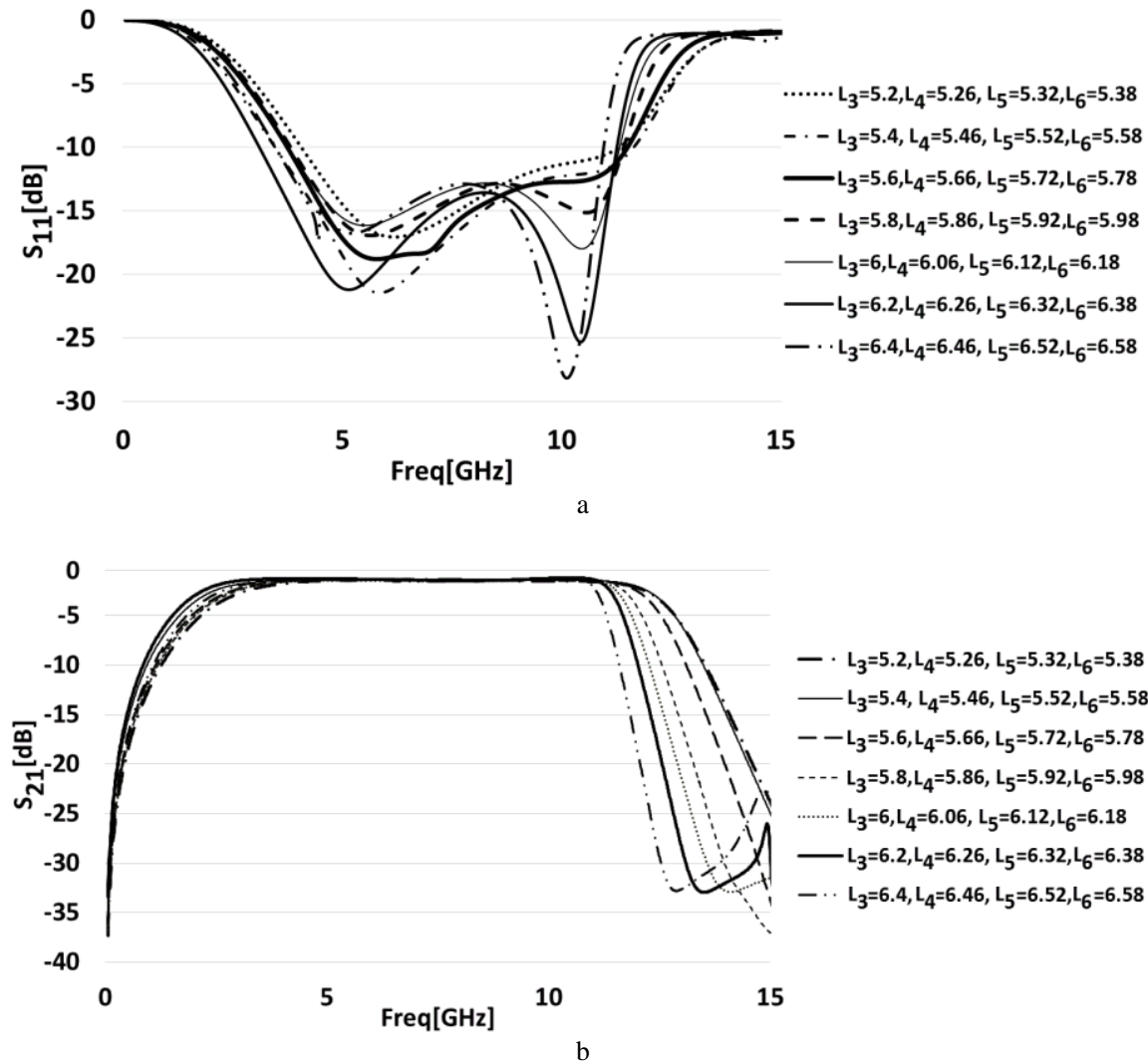

Fig.5. (a) $\mathrm{S}_{11}$ performance and (b) $\mathrm{S}_{21}$ performance for different DGS lengths $\left(\mathrm{L}_{3}, \mathrm{~L}_{4}, \mathrm{~L}_{5}\right.$ and $\left.\mathrm{L}_{6}\right)$.

\subsection{Effect of coupling finger lengths}

The $\mathrm{S}$ parameter results for different coupling finger lengths $\left(\mathrm{L}_{7}, \mathrm{~L}_{8}, \mathrm{~L}_{9}\right.$ and $\left.\mathrm{L}_{10}\right)$ which lie on the top plane of the designed BPF are shown in Fig. 6. For $5.8 \mathrm{~mm}$ length i. e. the designed length, proper pass band is generated.

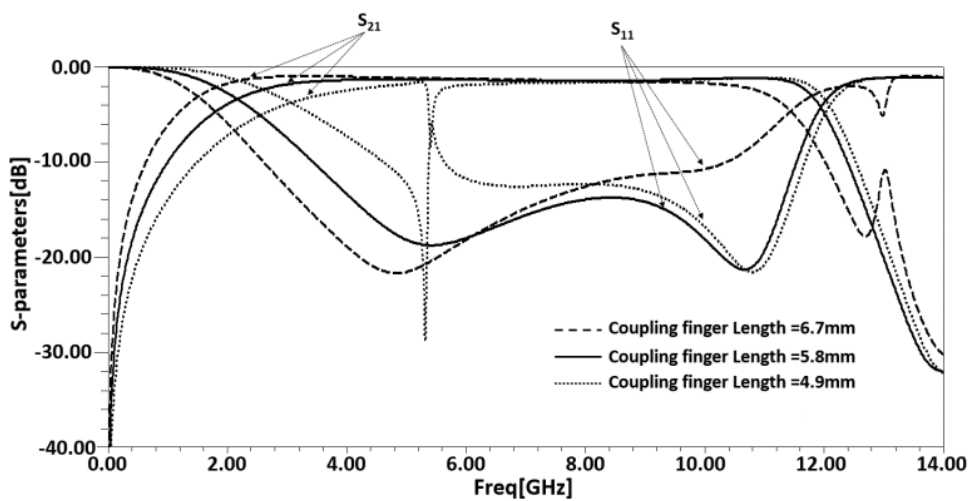

Fig.6. Comparison of Simulated S parameters for different coupling finger lengths $4.9 \mathrm{~mm}, 5.8 \mathrm{~mm}, 6.7 \mathrm{~mm}$ respectively 
The undesired modes are generated due to the notch for $4.9 \mathrm{~mm}$ coupling finger length. The rejection band at upper frequency edge is not at the desired level for $6.7 \mathrm{~mm}$ length. The change in length also changes the cut off frequencies and so it is observed that the pass band is controlled by the coupling length.

Comparing the results from above three tables, the optimized dimensions of the UWB BPF are fabricated and the final design dimensions are $: \mathrm{L}=20 \mathrm{~mm}, \mathrm{~W}=13 \mathrm{~mm}, \mathrm{~W}_{1}=\mathrm{W}_{2}=3 \mathrm{~mm}, \mathrm{~L}_{1}=\mathrm{L}_{2}=6.5 \mathrm{~mm}, \mathrm{~W}_{\mathrm{a}}=0.7$ $\mathrm{mm}, \mathrm{L}_{3}=6 \mathrm{~mm}, \mathrm{~L}_{4}=6.06 \mathrm{~mm}, \mathrm{~L}_{5}=6.12 \mathrm{~mm}, \mathrm{~L}_{6}=6.18 \mathrm{~mm}, \mathrm{~L}_{7}=\mathrm{L}_{8}=\mathrm{L}_{9}=\mathrm{L}_{10}=5.8 \mathrm{~mm}, \mathrm{~S}=0.17 \mathrm{~mm}, \mathrm{~W}_{5}=$ $0.2 \mathrm{~mm}, \mathrm{~g}_{1}=\mathrm{g}_{3}=3.04 \mathrm{~mm}, \mathrm{~g}_{2}=3.6 \mathrm{~mm}$ as labeled in Fig. 1 .

\section{The UWB-BPF simulations}

In this design of UWB BPF, a dual mode MMR is properly made so that its two resonant modes lie close to the lower end and upper end of the specified UWB passband. The performance of the bandpass filter is improved by the inclusion of the DGS array in the ground plane and the coupling finger lengths in the top plane to cover the UWB frequency range. The simulation results using ansoft HFSS show an operating passband (where $\mathrm{S}_{11}<-14 \mathrm{~dB}$ ) that extend from $2.78 \mathrm{GHz}-10.95 \mathrm{GHz}$ is shown in Fig. 7 (a). The proposed BPF has a wide $-30 \mathrm{~dB}$ rejection in the upper stop band upto $16.8 \mathrm{GHz}$ is shown in Fig. 7 (b).
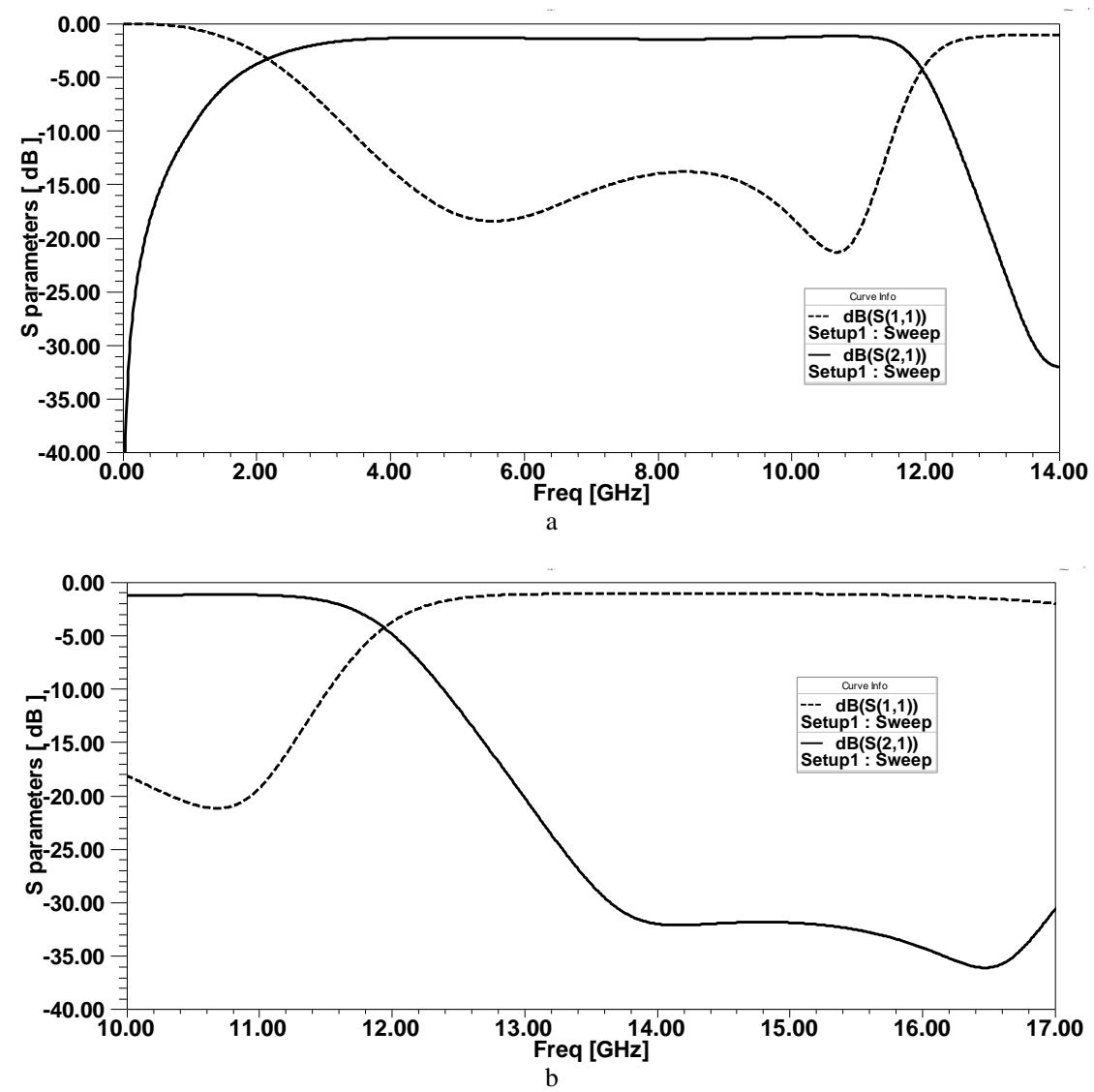

Fig.7. (a) Simulated S parameters performance of proposed UWB BPF; (b) Upper stop band performance 


\section{Group delay of the UWB-BPF}

Group delay is defined as the rate of change of transmission phase angle with respect to frequency. The proposed UWB-BPF group delay is obtained from the simulated as well as measured results as shown in Fig. 8. It is clear that the variations in the group delay are around $0.2 \mathrm{~ns}$ for the frequency band of $2.78-10.95 \mathrm{GHz}$.

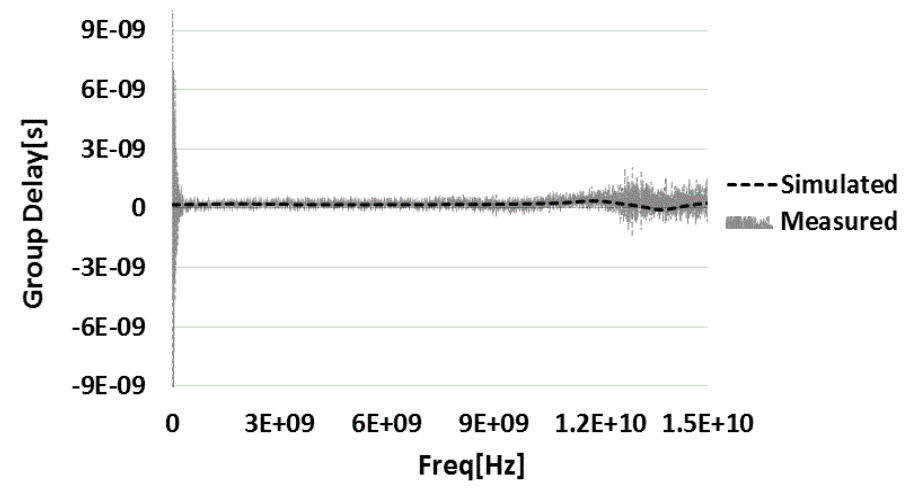

Fig.8. Simulated and measured group delay of proposed UWB BPF.

\section{Fabrication and measurements}

A prototype of the proposed UWB-BPF with MMR and transverse DGS slots is fabricated as shown in Fig. 9 (a) with top view and Fig. 9 (b) with bottom view. It is also measured by VNA. The substrate used to realize the designed filter is FR-4 epoxy with dielectric constant $\left(\varepsilon_{r}\right)=4.4$, substrate height $(\mathrm{h})=1.6 \mathrm{~mm}$ and has a compact size of $20 \mathrm{~mm} \times 13 \mathrm{~mm}$.

The simulated and measured results are in good agreement and show good in-band filtering performance and sharp selectivity as shown in Fig. 10.

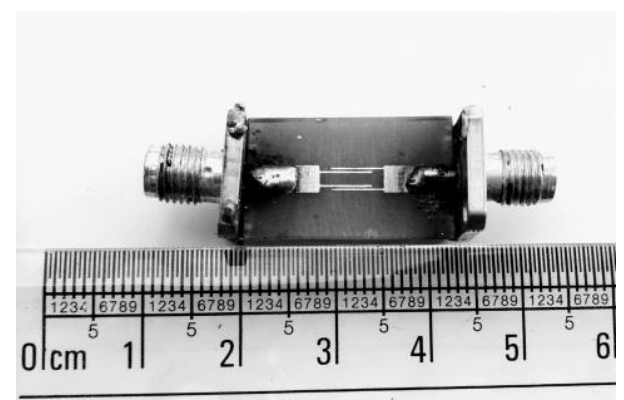

a.

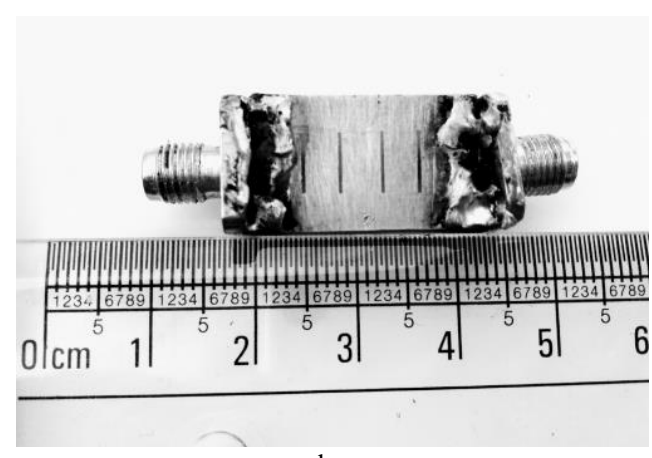

b.

Fig.9. The photograph of the fabricated UWB-BPF (a) Top view; (b) Bottom view 


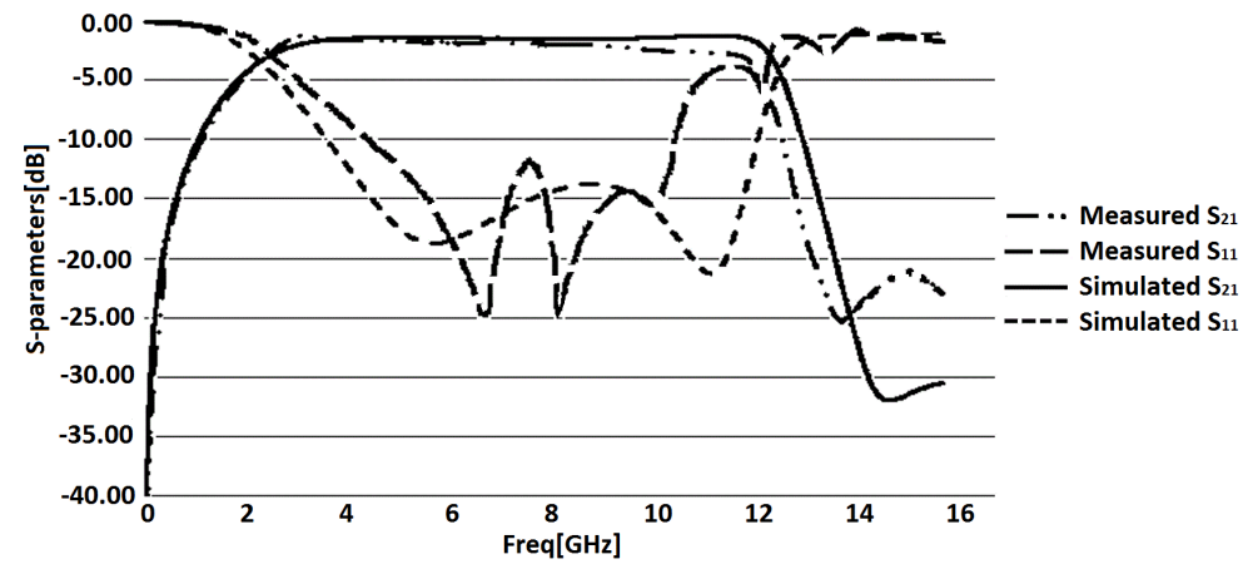

Fig.10. The measured and simulated UWB-BPF S parameters performance.

\section{Conclusions}

A microstrip UWB BPF using a dual MMR and the transverse narrow DGS array is proposed here in this paper. The MMR structure is analyzed and the corresponding transmission line equivalent model is given. The parametric analysis of different variables of the DGS array used in the design is carried out to obtain the optimized dimensions. The filter is modelled and simulated with Ansoft HFSS software. The designed filter is realized using photolithographic technique. It is seen that the DGS array improves the upper stop band of the UWB BPF. The simulated and measured results show a wide FBW of $119 \%$ and insertion loss is less than -1.0 $\mathrm{dB}$ throughout the pass band of $2.78 \mathrm{GHz}-10.95 \mathrm{GHz}$. The simulation results are in good agreement with the measured ones and a sharp selectivity is achieved. The BPF has more than $-30 \mathrm{~dB}$ high rejection in the upper stop band up to $16.8 \mathrm{GHz}$.

\section{References}

[1] FCC, Revision of Part 15 of the Commission's Rules Regarding Ultra-Wideband Transmission Systems Federal Communications Commission, Tech. Rep. 2002 , ET-Docket 98-153, FCC02-48.

[2] Awai I., Kundu A. C., and Yamashita T., Equivalent circuit representation and explanation of attenuation poles of a multimode dielectric-resonator bandpass filter, IEEE Trans. Microwave Theory Tech. 1998, Vol. 46, 2159-2163.

[3] Saito A., Harada H., and Nishikata A., Development of bandpass filter for ultra wideband (UWB) communication systems, IEEE Conference on Ultra Wideband Systems and Technologies 2003, 76-80.

[4] Ishida H. and Araki K., Design and analysis of UWB bandpass filter with ring filter, IEEE MTT-S Microwave Symp. Dig. 2004, 1307-1310.

[5] Zhu L., Sun S., and Menzel W., Ultra-wideband (UWB) bandpass filters using multiple-mode resonator, IEEE Microwave and Wireless Components Lett. 2005, Vol. 15, No. 11, 796-798.

[6] Yang G., Jin M. R., Geng J., Huang X., and Xiao G., Ultra wide band bandpass filter with hybrid quasilumped elements and defected ground structure, IET Microw. Antenna Propag. 2007, Vol. 1,No. 3, 733736.

[7] L. Rui, Z. Lei, Compact UWB Bandpass Filter Using Sub-Loaded Multiple-Mode Resonator, IEEE Microwave and Wireless Components Lett. 2007, Vol. 17, 40-42.

[8] Sun Sheng and Zhu Lei, Multimode-Resonator-Based Bandpass Filters, IEEE Microwave Magazine, 2009, 1527-3342/09/\$25.00@2009 IEEE, pp. 88-98. 
[9] Ma K., Leong K. C. B., Jayasuriya R. M., and Yeo K. S., A wideband and high rejection multimode bandpass filter using stub perturbation, IEEE Microwave and Wireless Components Lett. 2009, Vol. 19, 24-26.

[10] Pirani S., Nourinia J., and Ghobadi C., Band-Notched UWB BPF Design Using Parasitic Coupled Line, IEEE Microwave and Wireless Components Lett. 2010, Vol. 20, No. 8, 444-446.

[11] Chu Qing-Xin, Wu Xiao-Hu, and Tian Xu-Kun, Novel UWB Bandpass Filter Using Stub-Loaded Multiple-Mode Resonator, IEEE Microwave And Wireless Components Letters, 2011, Vol. 21, No. 8.

[12] Wang J., Liu B., Zhao Y., Yuan C., and Deng H., Wide upper-stopband super-UWB BPF based on SCRLH transmission line structure, Electronics Letters, Vol. 47, No. 22, 2011.

[13] Singhal P. K., Mathur S., Baral R. N., Ultra- Wide microstrip band pass filter using short circuited stubs, Journal of Electrical and Electronics Engineering research, Vol. 3(6),pp.101-107,2011.

[14] Saini Yashika and Kumar MIthilesh, Performance analysis of chebyshev UWB bandpass filter using defected ground structure, IEEE International Conference of Advances in Computing, Communications and Informatics (ICACCI), 2014, 978-1-4799-3080-7.

[15] Song Chaowei, Li Sha,Wang Yuzhu,Wang Xu, A novel ultra-wideband filter with wider stopband employing multiple-mode resonator and low-pass filter, IEEE International conference on Electronic Packaging Technology(ICEPT), 2015, DOI: 10.1109/ICEPT.2015.7236646.

[16] Lu Jiayuan, Wang Jianpeng and Gu Hui, Design of compact balanced ultra-wideband bandpass filter with half mode dumbbell DGS, Electronics Letters, 2016, Vol. 52 No. 9 pp. 731-732.

[17] Zhu L., and $\mathrm{Wu} \mathrm{K}$., Unified equivalent-circuit model of planar discontinuities suitable for field theorybased CAD and optimization of M(H)MIC, IEEE Trans. Microw. Theory Tech., 1999, 47, (9), pp.- 15891602.

[18] Zhu L., Bu H. and Wu K., Broadband and compact multi-pole microstrip bandpass filters using ground plane aperture technique, IEE Proceedings - Microwaves Antennas and Propagation, Vol. 149, No. 1, February 2002.

\section{Authors' Profiles}

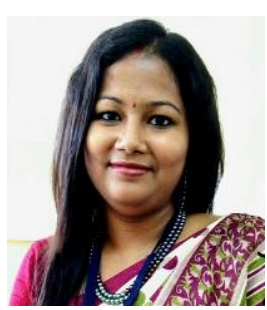

Aditi Sengupta was born in 1984. She received her B.Tech and M.Tech degree from West Bengal University of Technology in 2007 and 2011 respectively. She had worked as an Assistant lecturer in the College of Science and Technology, Bhutan during 2007-2009. Currently she is an Assistant Professor in the Department of Electronics and Communication Engineering, Guru Nanak Institute of Technology, Kolkata, India. Her field of interest includes Microwave circuits, EMI/EMC and Microstrip Antennas. She is a member of Institute of Electrical and Electronics Engineers (IEEE) and life member of Society of EMC Engineers (India) (SEMCEI).

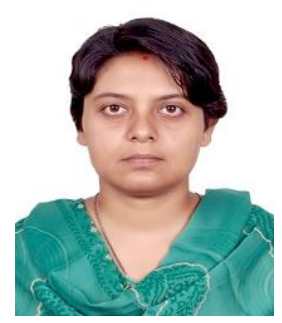

Somdotta Roy Choudhury was born in 1982. She received her B.Tech degree in Electronics and Communication Engineering from West Bengal University of Technology, India in the year 2007 and ME degree in the year 2009 from Bengal Engineering and Science University, Shibpur, India in the department of Electronics and Telecommunication Engineering. She obtained the $\mathrm{PhD}$ (Engineering) degree in the year 2017 from Indian Institute of Engineering Science \& Technology, Shibpur. Her current research interests include the planar circuits, Microstrip filters, antenna elements, EBG, FSS and metamaterial Structures etc. 


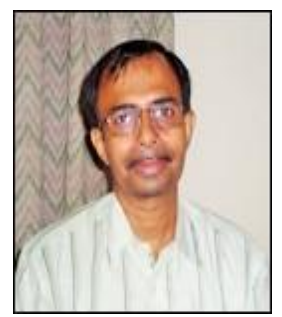

Santanu Das was born in 1968. He received the B.E. degree in Electronics and Telecommunication Engineering from Bengal Engineering College of Calcutta University (India) in 1989 and M.E. degree in Microwave Engineering from Jadavpur University, Calcutta, in 1992. He obtained Ph.D. (Engineering) degree from Jadavpur University in 1998. He joined the Indian Institute of Engineering Science \& Technology, Shibpur (Formerly Bengal Engineering and Science University), India in the year 1998, as a Lecturer in the Dept. of Electronics and Telecommunication Engineering and presently holds the post of Professor. His current research interests include microstrip circuits, FSS, antenna elements and arrays. He is a life member of the Institution of Engineers, India (IE).

How to cite this paper: Aditi Sengupta, Somdotta Roy Choudhury, Santanu Das," Design of an UWB Bandpass Filter Using Dual MMR with Highly Attenuated Upper Stopband Using DGS", International Journal of Wireless and Microwave Technologies(IJWMT), Vol.8, No.3, pp. 58-69, 2018.DOI: 10.5815/ijwmt.2018.03.06 